\title{
Caustic colitis due to formalin enema
}

\author{
Miguel Muñoz-Navas, MD \\ Luis García-Villarreal, MD \\ Service of Gastroenterology Clinica Universitaria Navarra \\ Pamplona, Navarra, Spain
}

Colitis has been reported by rectal instillation of a variety of agents: soap enemas, ${ }^{1,2}$ water-soluble contrast media, ${ }^{3}$ hydrogen peroxide, ${ }^{4,5}$ vinegar, potassium dichromate, potassium permanganate, copper sulfate, brown sugar, ${ }^{6}$ glutaraldehyde, ${ }^{4}$ non-steroidal anti-inflammatory agents, ${ }^{7}$ and ethyl alcohol. ${ }^{8}$

We report a 54-year-old man, who accidentally received a $100-\mathrm{ml}$ enema of $10 \%$ formalin. Within minutes the patient experienced severe sharp pain located in the left lower abdomen followed by rectal bleeding.

Five days later, colonoscopic examination revealed an edematous and erythematous mucosa with multiple petechiae and superficial erosions in the rectum and sigmoid up to $25 \mathrm{~cm}$ from the anal verge. Histology showed a nonspecific chronic colitis, superficial erosions, lymphocytes and plasma cells infiltrate, and erythrocyte extravasation.

Following treatment with corticosteroid enemas rapid improvement was achieved. Two months later he was asymptomatic and endoscopy showed a distensible rectum with almost complete resolution of colitis. Biopsies revealed a very mild non-specific colitis in a regenerative phase. Currently, 2 years later, the patient is asymptomatic.

The severity of the acute colonic damage after caustic enema depends on the chemical constituent, the concentration of the solution as well as the duration of mucosal contact. $^{1,3}$

Between the third and fifth week, a cicatrization phase begins; afterward the lesion may progress to stricture formation, ${ }^{3}$ a complication that did not occur in our patient. Corticosteroids or ACTH have been employed, ${ }^{1,8}$ but we have not found other cases managed with corticosteroid enemas. To our knowledge, this is the first reported case of acute colitis due to rectal administration of formalin.

\section{$\underline{\text { REFERENCES }}$}

1. Kim SK, Cho C, Levinsohn EM. Caustic colitis due to detergent enema. AJR 1980;134:397-8.

2. $\quad$ Pike BF, Phillippi PJ, Lawson EH. Soap colitis. N Engl J Med 1971;285:217-8.

3. Fortson WC, Tedesco FJ. Drug-induced colitis: a review. Am J Gastroenterol 1984;79:878-83.

4. Jonas G, Mahoney A, Murray J, Gertler S. Chemical colitis due to endoscope cleaning solutions: a mimic of pseudomembranous colitis. Gastroenterology 1988;95:1403-8.

5. Bilotta JJ, Waye JD. Hydrogen peroxide enteritis: the "snow white" sign. Gastrointest Endosc 1989;35:428-30.

6. Segal I, Tim LO, Hamilton DG, et al. Ritual-enema-induced colitis. Dis Colon Rectum 1979;22:195-9.

7. Gizzi G, Villani V, Brandi G, Paganelli GM, Di Febo G, Biasco G. Ano-rectal lesions in patients taking suppositories containing non-steroideal antiinflammatory drugs (NSAID). Endoscopy 1990;22:146-8.

8. Herrerías JM, Muniain MA, Sánchez S, Garrido M. Alcoholinduced colitis. Endoscopy 1983;15:121-2. 